\title{
A Model for Educational Simulation of Hemodynamic Transitions at Birth
}

\author{
CARLA D. SÁ-COUTO, PETER ANDRIESSEN, WILLEM L. VAN MEURS, DIOGO AYRES-DE-CAMPOS, \\ AND PEDRO M. SÁ-COUTO
}

\begin{abstract}
INEB_Instituto de Engenharia Biomédica [C.D.S.-C., W.L.M., D.A.-C., P.M.S.-C.], Porto, 4200-465, Portugal; Neonatal Intensive Care Unit [P.A.], Máxima Medical Center, Veldhoven, 5500 MB, The Netherlands; Department of Anesthesiology [W.L.M.], University of Florida College of Medicine, Gainesville, Florida 32610; Departamento de Engenharia Electrotécnica e de Computadores [W.L.M.], Faculdade de Engenharia da Universidade do Porto, Porto, 4200-465, Portugal; Faculdade de Medicina da Universidade do Porto [D.A.-C.], Hospital de S. João, Porto, 4200-319, Portugal; and Department of Mathematics [P.M.S.-C.], University of Aveiro, Aveiro,
\end{abstract} 3810-193, Portugal

\begin{abstract}
Birth is characterized by swift and complex transitions in hemodynamic and respiratory variables. Unrecognized pathologies or incidents may quickly become fatal or cause permanent damage. This article introduces an essential component of an acute perinatal care simulator, namely a model for educational simulation of normal hemodynamic transitions seen during and shortly after birth. We explicitly formulate educational objectives and adapt a preexisting model for the simulation of neonatal cardiovascular physiology to include essential aspects of fetal hemodynamics. From the scientific literature, we obtain model parameters that characterize these aspects quantitatively. The fetal model is controlled by a time- and event-based script of changes occurring at birth, such as onset of breathing and cord clamping, and the transitory phase up to $24 \mathrm{~h}$ after birth. Comparison of simulation results with published target data confirms that realistic simulated hemodynamic vital signs are achieved. (Pediatr Res 67: 158-165, 2010)
\end{abstract}

$\mathrm{P}$ erinatal acute care is associated with specific clinical demands and challenges. The relatively small number of acute care cases occurring in many institutions, together with the presence of senior staff assuming the responsibility for their management, may hinder the establishment of adequate training for less experienced individuals. In other areas of acute care medicine, realistic simulators contribute to training of healthcare professionals and to patient safety.

Clinically relevant learning objectives for medical staff in Neonatology include the recognition of cardiovascular signs and symptoms occurring in pathologies that manifest shortly after birth, such as persistent pulmonary hypertension, left ventricular overload by a patent ductus arteriosus (DA), myocardial depression, and hemorrhage.

Received May 24, 2009; accepted September 15, 2009.

Correspondence: Willem van Meurs, PhD, INEB-Instituto de Engenharia Biomédica, Divisão de Sinal e Imagem, Campus FEUP, Edifício I poente, Rua Roberto Frias, s/n, 4200-465 Porto, Portugal; e-mail: wvanmeurs@ineb.up.pt

Supported in part by Máxima Medical Center, Veldhoven, The Netherlands, and the Instituto de Engenharia Biomédica, Porto, Portugal.

Dr. van Meurs receives a meaningful fraction of his income from royalties and consulting with Medical Education Technologies, Inc. Carla Sá Couto and Drs. van Meurs and Ayres de Campos received a grant from Medical Education Technologies, Inc., for work on a different project.

Supplementary digital content is available for this article. Direct URL citations appear in the printed text, and links to the digital files are provided in the HTML text of this article on the journal's Web site (www.pedresearch.org).
This article introduces a fundamental component of a perinatal acute care simulator, namely a simulation engine, for normal hemodynamic transitions from the fetal to the early neonatal period. A simulation engine can contribute to a life-like training environment by providing real-time, automatic evolution of clinical signs and monitored signals and of their response to therapeutic interventions. To be able to simulate normal physiology and provide a platform for future simulation of the above-mentioned incidents and pathologies, it is necessary that the engine reflect essential aspects of fetal hemodynamics and its subsequent transition to the neonate. Among others, structures such as lungs, placenta, heart, systemic arterial circulation, and the various fetal shunts need to be included. The simulation engine should be able to simulate realistic blood pressures and flow rates in these structures during fetal, transitional, and neonatal periods.

\section{METHODS}

The proposed simulation engine for normal hemodynamic transitions from the fetal to the early neonatal period consists of a fetal hemodynamic model controlled by a time- and event-based script (1). The script triggers events occurring at birth such as onset of breathing, cord clamping, and the transitory phase up to $24 \mathrm{~h}$ after birth, via changes to selected model parameters. The Instituto de Engenharia Biomédica, Porto, Portugal, and the Máxima Medical Center, Veldhoven, The Netherlands, approved this study.

Fetal hemodynamic model. In this study, we used an adaptation of a previously described model for educational simulation of the neonatal circulation $(2,3)$. The latter was based on the linearized, improved model of cardiovascular physiology, originally presented by Beneken (1965, $\mathrm{PhD}$ thesis), which is also the basis for the model of cardiovascular physiology of the human patient simulator (HPS; developed at the University of Florida and commercially available from Medical Education Technologies, Inc., Sarasota, FL) and for a recently published model of infant cardiovascular physiology (4). In the discussion section, we will come back to other fetal hemodynamic models.

To reflect the unique aspects of fetal circulation, the neonatal model was adapted as follows (Fig. 1):

- the DA was included between the pulmonary arteries and the aorta (part of the intrathoracic arteries compartment);

- the foramen ovale (FO) was included between the atria with a valve-like flap, and;

- the placental circulation (including the ductus venosus) was placed in parallel with the systemic circulation, returning all flow to the intrathoracic veins compartment.

Abbreviations: DA, ductus arteriosus; FO, foramen ovale; PVR, pulmonary vascular resistance; TSR, total systemic resistance 


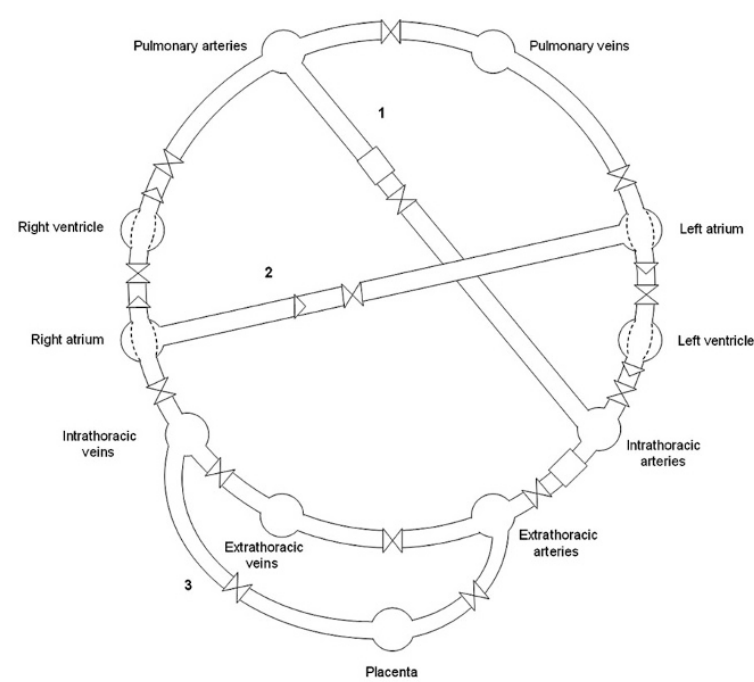

Figure 1. Hydraulic analog for the fetal cardiovascular model. Fetal shunts: 1-ductus arteriosus, 2-foramen ovale, 3-ductus venosus. Fetal circulation represented by 11 compliant compartments. Heart chambers compartments are represented by time-variant elastances to mimic heart contractility. Connections between compartments represent blood flow and include vessel resistance to the passage of blood. Heart valves are included in the atrial and ventricular outflows. Inertial behavior of the blood is included in the DA and in the intrathoracic arteries outflow.

The proposed fetal hemodynamic model consists of two major parts: The heart and seven vascular compartments. We refer to previous studies by our group for a detailed description of the mathematics associated with implementation of the model and similar extensions (2-4).

Numerical values for most model parameters were obtained directly from the scientific literature (5-14). Numerical values for a few parameters that are specific to our model needed to be derived (Supplemental Methods, Supplemental Digital Content, http://links.lww.com/PDR/A57). Table 1 presents the complete parameter set for a full-term fetus with an assumed weight of $3 \mathrm{~kg}$.

Scripted transitions at birth. Scripted transitions can be automatic or controlled by the simulation instructor. Twenty-four hours after birth, transitions are complete and the model structure (but not all parameter values) matches the previously published model for a 1-week-old neonate. The following subsections describe the scripted model parameter changes in detail.

Intrathoracic pressure. During fetal life, the bronchoalveolar tract is filled with fetal lung fluid, maintaining the lungs in a distended state and with an intrathoracic pressure of around $0 \mathrm{~mm} \mathrm{Hg}(13,14)$. At birth, the fluid in the bronchoalveolar tract is replaced by air. In spontaneously breathing newborns, the diaphragm contracts during inspiration, thereby lowering the intrathoracic pressure toward negative values of approximately $-3 \mathrm{~mm} \mathrm{Hg}(14,15)$.

Pulmonary vascular resistance (PVR). Immediately after birth, concurrent with the onset of breathing, PVR decreases abruptly (16). After this period, there is a more gradual decline in resistance over the following days and weeks $(16,17)$. From the studies of Dawes et al. (18) in fetal lambs, it was possible to estimate a reduction in PVR of $74 \%$ after the start of ventilation. A neonatal PVR value between 0.75 and $0.9 \mathrm{~mm} \mathrm{Hg} \cdot \mathrm{mL}^{-1} \cdot \mathrm{s}$ was reported by Brook et al. (19), and it was assumed that this is reached by the end of the first week of life. In our model, PVR is distributed over model parameters RPP and RLAIN (see Table 1 for abbreviations). An exponential was used to mimic the initial rapid decrease immediately after birth, and a linear function to reproduce the slower decrease thereafter, reported here only for the first $24 \mathrm{~h}$ of life:

$$
\operatorname{RPP}(t)= \begin{cases}\operatorname{RPP}_{0}\left(1-0.74\left(1-e^{-6 t}\right)\right) & \text { for } 0 \leq t \leq 2 h \\ \operatorname{RPP}_{0}\left(0.26-9.5 \times 10^{-4}(t-2)\right) & \text { for } 2<t \leq 24 h\end{cases}
$$

where $\mathrm{RPP}_{0}$ is the resistance in pulmonary peripheral vessels for a normalterm fetus. Similarly, for RLAIN:

$$
\operatorname{RLAIN}(t)= \begin{cases}\operatorname{RLAIN}_{0}\left(1-0.74\left(1-e^{-6 t}\right)\right) & \text { for } 0 \leq t \leq 2 h \\ \operatorname{RLAIN}_{0}\left(0.26-9.5 \times 10^{-4}(t-2)\right) & \text { for } 2<t \leq 24 h\end{cases}
$$

Systemic vascular resistance. With cord clamping, total systemic resistance (TSR) approximately doubles (20). An initial rapid rise in TSR is followed by a slower, more sustained increase over time. The mechanisms behind this considerable increase are not fully understood, but it is thought that there are at least three contributing factors: removal of the low-resistance placental bed, catecholamine release $(21,22)$, and a high sympathetic tone in the immediate postnatal period (23). Measurements of TSR in full-term human neonates during the first $24 \mathrm{~h}$ of life are available from several sources (24-26). Based on these data, the following piecewise linear approximation was established:

$$
\operatorname{TSR}(t)= \begin{cases}0.0846 t+3.45 & \text { for } 1 / 60 \leq t \leq 12 h \\ 0.00420 t+4.42 & \text { for } 12<t \leq 24 h\end{cases}
$$

Cord clamping is assumed to take place at $1 \mathrm{~min}$. Only the peripheral vessel resistance $[\operatorname{RSP}(\mathrm{t})]$ is increased, whereas the resistances of extrathoracic arteries and veins (RETHA and RETHV) remain constant. TSR $(t)$ corresponds to the sum of these three parameters.

DA resistance. It is well known that the DA constricts rapidly after birth, with functional closure occurring within 12 to $36 \mathrm{~h}$ in the majority of term infants. Experimental data for DA diameter (DAD) changes in humans can be found in Rasanen et al. (11), for the full-term fetus, and in several other publications (25-28) for term neonates, during the first $24 \mathrm{~h}$ of life. To model DA closure, we used a dynamic resistance that increases with neonatal age. The following curve of the DAD in centimeters, as a function of age $t$ in hours, was fitted to these data (Sá Couto, unpublished data):

$$
\mathrm{DAD}(t)=0.29 e^{-0.43 t}+0.30 e^{-0.054 t}
$$

Migliavacca et al. (29) present an application of Poiseuille's law to calculate ductus arteriosus resistance (DAR) as a function of its diameter:

$$
\operatorname{DAR}(t)=\frac{K}{\operatorname{DAD}(t)^{4}}
$$

where $\mathrm{K}$ is a proportionality constant in $\mathrm{mm} \mathrm{Hg} \cdot \mathrm{s} \cdot \mathrm{cm}$.

In our model, $\mathrm{K}$ was set to $0.0145 \mathrm{~mm} \mathrm{Hg} \cdot \mathrm{s} \cdot \mathrm{cm}$ to match fetal DAR and DAD (0).

Software implementation. Model equations were numerically integrated using the Euler forward method with a step size of $0.1 \mathrm{~ms}$. All simulations were implemented in Matlab V7.5(R2007b; MathWorks, Inc.) on a personal computer with an 2.33-GHz Intel Core Duo processor.

\section{RESULTS}

To evaluate the realism of the described simulation engine, we compared simulation results with target data. This comparison was performed at three physiologically and educationally relevant stages: Term fetus, ventilation and cord clamping, and the evolution during the first $24 \mathrm{~h}$ of life.

Term fetus. Table 2 presents target data and simulation results for the term fetus. Note that to facilitate comparison across species, all flow rates are normalized to fetal weight. All but one of the simulated flow rates fall within one SD of the mean target data obtained in the term fetal lamb $(30,31)$. Pulmonary blood flow rate is the exception, but like the other flow rates, matches human target data (11). Combined ventricular stroke volume (CVSV) and output (CVO) also match human target data (8). Simulated arterial blood pressures are within one SD of animal target data $(30,31)$. This comparison demonstrates that the fetal model has clinically appropriate ventricular outputs, flow rates, and pressures at baseline.

Ventilation and cord clamping. Table 3 presents target data (30) and simulation results for newborn ventilation and ventilation with cord clamping. Comments concerning the target data are included in the discussion section. The ventilation column shows that all simulated output variables are within one SD of the target data, with the exception of arterial pressures that are within two SDs. Ventilation with cord 
Table 1. Fetal cardiovascular model parameters (assumed weight: $3 \mathrm{~kg}$ )

\begin{tabular}{|c|c|c|c|c|}
\hline Part of circulation & Compartment & Parameter description & Parameter name & Parameter value \\
\hline \multirow{2}{*}{ Total circulation } & All, except placenta & Initial total blood volume & VTOTAL & 234 \\
\hline & Placenta & Initial total blood volume & VPL & 135 \\
\hline Heart & Atria and ventricles & Heart rate & HR & 148 \\
\hline Intrathoracic & All intrathoracic & Average intrathoracic pressure & PTH & 0.00 \\
\hline \multirow[t]{9}{*}{ Left heart } & Left atrium & $\begin{array}{l}\text { Resistance to forward flow including pulmonary } \\
\text { venous resistance }\end{array}$ & RLAIN & 3.60 \\
\hline & & Mitral valve resistance & RLAOUT & 0.0600 \\
\hline & & Diastolic elastance & ELAMIN & 0.330 \\
\hline & & Maximum systolic elastance & ELAMAX & 1.00 \\
\hline & & Unstressed volume & VLAU & 0.00 \\
\hline & Left ventricle & Aortic valve and intrathoracic artery resistance & RLV & 0.0180 \\
\hline & & Diastolic elastance & ELVMIN & 0.324 \\
\hline & & Maximum systolic elastance & ELVMAX & 12.0 \\
\hline & & Unstressed volume & VLVU & -4.00 \\
\hline \multirow[t]{14}{*}{ Systemic circulation } & Intrathoracic arteries & Elastance & EITHA & 7.69 \\
\hline & & Unstressed volume & VITHAU & 6.86 \\
\hline & Extrathoracic arteries & Blood flow inertia & LETHA & 0.00200 \\
\hline & & Resistance & RETHA & 0.821 \\
\hline & & Elastance & EETHA & 6.25 \\
\hline & & Unstressed volume & VETHAU & 18.1 \\
\hline & Peripheral vessels & Resistance & RSP & 2.30 \\
\hline & Extrathoracic veins & Resistance (to forward flow) & RETHV & 0.336 \\
\hline & & Elastance & EETHV & 0.250 \\
\hline & & Unstressed volume & VETHVU & 47.5 \\
\hline & Intrathoracic veins & Elastance & EITHV & 0.500 \\
\hline & & Unstressed volume & VITHVU & 56.5 \\
\hline & Ductus arteriosus & Resistance & $\mathrm{RDA}$ & 0.120 \\
\hline & & Inertia & LDA & 0.0180 \\
\hline \multirow[t]{4}{*}{ Placental circulation } & Umbilical arteries & Resistance & RPLIN & 3.18 \\
\hline & Placenta & Elastance & EPL & 0.667 \\
\hline & & Unstressed volume & VPLU & 60.0 \\
\hline & $\begin{array}{l}\text { Umbilical vein and } \\
\text { ductus venousus }\end{array}$ & Resistance & RPLOUT & 0.546 \\
\hline \multirow[t]{10}{*}{ Right heart } & Right atrium & Resistance to forward flow & RRAIN & 0.0240 \\
\hline & & Tricuspid valve resistance & RRAOUT & 0.0600 \\
\hline & & Diastolic elastance & ERAMIN & 0.330 \\
\hline & & Maximum systolic elastance & ERAMAX & 1.00 \\
\hline & & Unstressed volume & VRAU & 0.00 \\
\hline & Right ventricle & Pulmonic valve and pulmonary artery resistance & RRV & 0.0180 \\
\hline & & Diastolic elastance & ERVMIN & 0.324 \\
\hline & & Maximum systolic elastance & ERVMAX & 12.0 \\
\hline & & Unstressed volume & VRVU & -4.00 \\
\hline & Foramen ovale & Resistance & RFO & 0.214 \\
\hline \multirow[t]{5}{*}{ Pulmonary circulation } & Pulmonary arteries & Elastance & $\mathrm{EPA}$ & 6.25 \\
\hline & & Unstressed volume & VPAU & 40.5 \\
\hline & Peripheral vessels & Resistance & RPP & 7.82 \\
\hline & Pulmonary veins & Elastance & EPV & 3.33 \\
\hline & & Unstressed volume & VPVU & 27.0 \\
\hline
\end{tabular}

Units: heart rate $-\mathrm{min}^{-1}$; resistances $-\mathrm{mm} \mathrm{Hg} \cdot \mathrm{mL}^{-1} \cdot \mathrm{s}$; elastances— $\mathrm{mm} \mathrm{Hg} \cdot \mathrm{mL}^{-1}$; volumes— $\mathrm{mL}$; inertia— $\mathrm{mm} \mathrm{Hg} \cdot \mathrm{mL}^{-1} \cdot \mathrm{s}^{2}$; $\mathrm{pressures}-\mathrm{mm} \mathrm{Hg}$.

occlusion results in a correct reversal of DA flow, from a predominantly right-to-left to a predominantly left-to-right shunt, and in increased left ventricular output. All simulated output variables are within or at one SD of target data. In the discussion section, we will analyze the single exception, DA right-to-left flow.

Evolution during the first $24 \boldsymbol{h}$ of life. Table 4 presents target data $(32,33)$ and simulation results for left ventricular stroke volume and output from the term fetus until the 24-h old neonate. With one exception, all simulation results are within one SD of target data. Left ventricular output at $12 \mathrm{~h}$ is one SD removed from the target data.
Table 5 presents target data $(34,35)$ and simulation results for arterial and atrial pressures $24 \mathrm{~h}$ after birth. All but one of the simulation results are within one SD of target data. Pulmonary arterial diastolic pressure is at one SD.

Figure 2 shows target data (36) and simulation results for the evolution of the mean aortic-pulmonary pressure difference during the first $24 \mathrm{~h}$ of life. These results demonstrate a plausible evolution of the simulated variable. The pulsatile nature of the model is illustrated in Figure 3, depicting the evolution of systemic and pulmonary arterial pressures in the fetus and at 2, 12, and $24 \mathrm{~h}$ after birth, respectively. 
Table 2. Target data $(8,11,30,31)$ and simulation results for the term fetus

\begin{tabular}{|c|c|c|c|c|c|}
\hline & \multicolumn{4}{|c|}{ Target data } & \multirow[b]{2}{*}{ Simulation results } \\
\hline & Mielke and Benda & Rasanen et al. & Teitel et al. & Anderson et al. & \\
\hline $\operatorname{CVSV}(\mathrm{mL} / \mathrm{kg})$ & 3 & 4 & - & - & 3 \\
\hline $\mathrm{CVO}(\mathrm{mL} / \mathrm{min} / \mathrm{kg})$ & 425 & 608 & $392 \pm 75$ & $462 \pm 194$ & 421 \\
\hline \multicolumn{6}{|l|}{ Flow rates (\% of CVO) } \\
\hline Right ventricle & 59 & 60 & $66 \pm 18$ & $60 \pm 27$ & 60 \\
\hline Left ventrficle & 41 & 40 & $34 \pm 11$ & $40 \pm 28$ & 40 \\
\hline DA & 46 & 39 & $\sim 57$ & $54 \pm 29$ & 42 \\
\hline Pulmonary & 11 & 21 & $8 \pm 5$ & $6 \pm 5$ & 18 \\
\hline FO & 33 & 19 & $26 \pm 12$ & $34 \pm 27$ & 22 \\
\hline Placenta & - & - & $35 \pm 12$ & - & 34 \\
\hline \multicolumn{6}{|c|}{ Mean pressures $(\mathrm{mm} \mathrm{Hg})$} \\
\hline Central venous & - & - & $3 \pm 3$ & - & 5 \\
\hline Right atrium & - & - & - & $2.4 \pm 0.6$ & 6 \\
\hline Left atrium & - & - & $3 \pm 3$ & $2.9 \pm 1.0$ & 5 \\
\hline Systemic arterial & - & - & $52 \pm 6$ & $45.4 \pm 5.7$ & 46 \\
\hline Pulmonary arterial & - & - & $53 \pm 8$ & $47.8 \pm 6.0$ & 47 \\
\hline
\end{tabular}

Target data-Mielke and Benda (8): values expressed as median, measurements in 222 human fetuses (13-41 weeks); Rasanen et al. (11): values expressed as mean, measurements in 63 human fetuses (mean gestational age: 38 weeks); Teitel et al. (30): values expressed as mean $\pm \mathrm{SD}$, measurements in 16 term fetal lambs; Anderson et al. (31): values expressed as mean $\pm \mathrm{SD}$, measurements in 12 near term fetal lambs.

- , data not available; $\sim$, data read from graph.

Table 3. Target data (30) and simulation results for transitions shortly after birth

\begin{tabular}{|c|c|c|c|c|}
\hline & \multicolumn{2}{|c|}{ Ventilation } & \multicolumn{2}{|c|}{ Ventilation with cord clamping } \\
\hline & Target data* (Teitel et al.) & Simulation results $\dagger$ & Target data $\ddagger$ (Teitel et al.) & Simulation results $\dagger$ \\
\hline CVSV (mL/kg) & - & 3 & - & 3 \\
\hline $\mathrm{CVO}(\mathrm{mL} / \mathrm{min} / \mathrm{kg})$ & $436 \pm 147$ & 438 & $359 \pm 92$ & 443 \\
\hline \multicolumn{5}{|l|}{$\begin{array}{l}\text { Flow rates } \\
\qquad(\% \text { of } \mathrm{CVO})\end{array}$} \\
\hline Right ventricle & $52 \pm 16$ & 55 & $40 \pm 10$ & 48 \\
\hline Left ventricle & $48 \pm 20$ & 45 & $60 \pm 18$ & 52 \\
\hline DA & $22 \pm 13(\mathrm{R}$ to $\mathrm{L}) 4 \pm 7(\mathrm{~L}$ to $\mathrm{R})$ & $22(\mathrm{R}$ to $\mathrm{L}) 0$ (L to $\mathrm{R})$ & $2 \pm 3(\mathrm{R}$ to $\mathrm{L}) 18 \pm 12(\mathrm{~L}$ to $\mathrm{R})$ & $11(\mathrm{R}$ to $\mathrm{L}) 11$ ( $\mathrm{L}$ to $\mathrm{R})$ \\
\hline Pulmonary & $33 \pm 22$ & 33 & $\sim 55$ & 52 \\
\hline FO & $15 \pm 9$ & 11 & $3 \pm 4$ & 0 \\
\hline Placenta & $31 \pm 17$ & 28 & $3 \pm 5$ & 0 \\
\hline \multicolumn{5}{|c|}{ Mean pressures (mm Hg) } \\
\hline Central venous & $4 \pm 3$ & 7 & $3 \pm 3$ & 6 \\
\hline Right atrium & - & 7 & - & 7 \\
\hline Left atrium & $7 \pm 4$ & 7 & $10 \pm 4$ & 7 \\
\hline Systemic arterial & $53 \pm 6$ & 41 & $58 \pm 16$ & 43 \\
\hline Pulmonary arterial & $55 \pm 9$ & 42 & $48 \pm 16$ & 43 \\
\hline
\end{tabular}

Target data: Teitel et al. (30): values expressed as mean $\pm \mathrm{SD}$; measurements in 16 term fetal lambs.

* Artificial ventilation of the lungs for $15 \mathrm{~min}$, with a gas mixture of $3 \% \mathrm{O}_{2}, 5 \% \mathrm{CO}_{2}$, and $92 \% \mathrm{~N}_{2}$ (mimicking fetal life); umbilical cord remained intact.

\$ Cord clamping after $30 \mathrm{~min}$ of artificial ventilation (initial 15 minutes with the gas mixture described above and last 15 minutes with $100 \% \mathrm{O}_{2}$ ) followed by another 15 minutes of artificial ventilation (with $100 \% \mathrm{O}_{2}$ ).

$\dagger$ Simulation times corresponding to target data. Mean intrathoracic pressure assumed to be $+2 \mathrm{~mm} \mathrm{Hg}$ to mimic the effect of artificial ventilation; DA resistance only starts to increase at minute 15 , to mimic DA sensitivity to oxygen levels.

-, data not available; , data read from graph; $\mathrm{R}$ to $\mathrm{L}$, right to left shunt; $\mathrm{L}$ to $\mathrm{R}$, left to right shunt.

Table 4. Target data (32,33) (mean $\pm S D$ ) and simulation results of the left ventricle performance from before birth to 24 hours after birth

\begin{tabular}{|c|c|c|c|c|c|c|c|c|c|c|}
\hline & \multicolumn{2}{|c|}{ Before birth } & \multicolumn{2}{|c|}{$1 \mathrm{~h}$} & \multicolumn{2}{|c|}{$2 \mathrm{~h}$} & \multicolumn{2}{|c|}{$12 \mathrm{~h}$} & \multicolumn{2}{|l|}{$24 \mathrm{~h}$} \\
\hline & $\begin{array}{l}\text { Target data } \\
\text { (Agata } \text { et al.) }\end{array}$ & $\begin{array}{l}\text { Simulation } \\
\text { results }\end{array}$ & $\begin{array}{l}\text { Target data } \\
\text { (Agata } \text { et al.) }\end{array}$ & $\begin{array}{l}\text { Simulation } \\
\text { results }\end{array}$ & $\begin{array}{l}\text { Target data } \\
\text { (Harada et al.) }\end{array}$ & $\begin{array}{l}\text { Simulation } \\
\text { results }\end{array}$ & $\begin{array}{l}\text { Target data } \\
\text { (Harada et al.) }\end{array}$ & $\begin{array}{l}\text { Simulation } \\
\text { results }\end{array}$ & $\begin{array}{l}\text { Target data (Agata, } \\
\text { Harada et al.) }\end{array}$ & $\begin{array}{l}\text { Simulation } \\
\text { results }\end{array}$ \\
\hline $\begin{array}{l}\text { Left ventricular } \\
\text { stroke volume } \\
(\mathrm{mL} / \mathrm{kg})\end{array}$ & $1.21 \pm 0.33$ & 1.14 & $2.25 \pm 0.37$ & 1.94 & $2.19 \pm 0.52$ & 1.95 & $1.76 \pm 0.39$ & 1.78 & $\begin{array}{l}2.02 \pm 0.42 \\
1.80 \pm 0.39\end{array}$ & 1.73 \\
\hline $\begin{array}{l}\text { Left ventricular } \\
\text { output } \\
\text { (mL/min/kg) }\end{array}$ & $170 \pm 46$ & 169 & $327 \pm 66$ & 287 & $291 \pm 72$ & 289 & $225 \pm 36$ & 264 & $\begin{array}{l}245 \pm 56 \\
222 \pm 52\end{array}$ & 257 \\
\hline
\end{tabular}

Target data: Agata et al. (32): echocardiographic measurements in 39 normal full-term fetuses and neonates from before birth until 24 hours after birth; Harada et al. (33): echocardiographic measurements in 22 normal term neonates from 2 until 24 hours after birth. 
Table 5. Target data $(34,35)$ (mean $\pm S D$ ) and simulation results of blood pressures at 24 hours after birth

\begin{tabular}{lccc}
\hline & \multicolumn{2}{c}{ Target data } & \\
\cline { 2 - 3 } & $\begin{array}{c}\text { Moss } \\
\text { et al. }\end{array}$ & $\begin{array}{c}\text { Emmanouilides } \\
\text { et al. }\end{array}$ & $\begin{array}{c}\text { Simulation } \\
\text { results }\end{array}$ \\
\hline Pressures (mm Hg) & & & \\
Atria & - & $2.3 \pm 1.2$ & 2.5 \\
$\quad$ Right & - & $4.5 \pm 1.4$ & 3.5 \\
$\quad$ Left & & & \\
Systemic arterial & $73.7 \pm 5.4$ & $73.3 \pm 7.5$ & 73.8 \\
$\quad$ Systolic & $52.2 \pm 4.3$ & $49.6 \pm 5.2$ & 48.9 \\
$\quad$ Diastolic & $61.9 \pm 4.4$ & $59.6 \pm 6.4$ & 59.8 \\
$\quad$ Mean & & & \\
Pulmonary arterial & $56.5 \pm 7.4$ & - & 50.4 \\
$\quad$ Systolic & $21.7 \pm 5.2$ & - & 27.1 \\
$\quad$ Diastolic & $38.3 \pm 6.1$ & - & 38.6 \\
$\quad$ Mean & & - & \\
\hline
\end{tabular}

Target data: Moss et al. (34): 24 measurements in 12 normal full-term neonates with mean age of $18 \mathrm{~h}(2-27 \mathrm{~h})$; Emmanouilides et al. (35): measurements in 23 normal full-term neonates with mean age of 26 hours $(6-35 \mathrm{~h})$.

- , data not available.

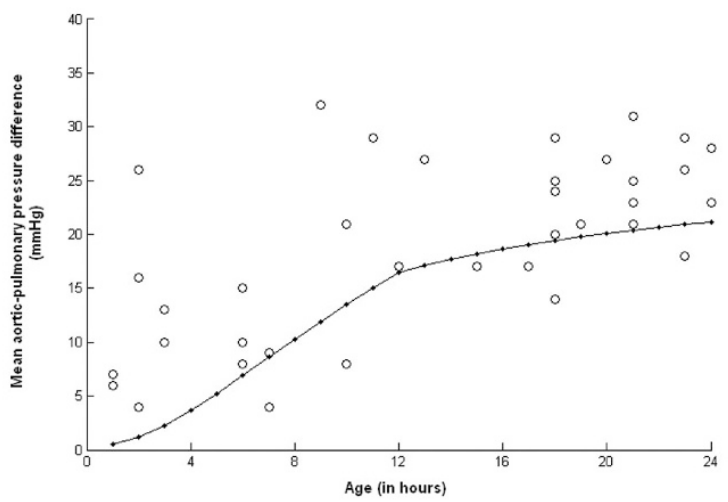

Figure 2. Mean aortic-pulmonary pressure difference in the first $24 \mathrm{~h}$ after birth. Open circles: Target data (36) from 39 normal-term human infants; Closed dots and line: Simulation results.

Figure 4 provides an overview of all simulated phenomena by presenting the scripted model parameters and the evolution of modeled flow rates and pressures from the fetus until the 24-h old neonate. With the onset of breathing, intrathoracic pressure decreases abruptly to negative values, as observed in spontaneously breathing newborns. In addition, PVR decreases considerably in the first minutes after birth (bottom panel). Consequently, arterial pressures increase and atrial pressures decrease (middle panel), but no relevant changes are observed in flow rates (top panel). An immediate result of cord clamping is the sudden increase in systemic resistance (bottom panel), causing an increase in systemic arterial blood pressure (middle panel) and the cessation of placental blood flow (top panel). Flow rate in the DA and pulmonary blood flow (top panel) are deeply affected by cord clamping. The continuous decrease of pulmonary resistance (bottom panel) further increases pulmonary blood flow (top panel). The increase in systemic resistance (bottom panel) and subsequent increase in left atrial pressure (middle panel) cause - at near constant right atrial pressure (middle panel) - a decrease in flow across the FO (top panel). The combination of increased left atrial pressure, because of higher pulmonary venous return, and diminished inferior vena cava return to the right atria results in a reversal of the left and right atrial pressures (middle panel), functionally closing the FO, as can be observed around minute 30 (top panel). From this time on, pulmonary inflow matches left ventricle flow rate (top panel). As PVR falls below systemic vascular resistance (bottom panel), the bidirectional DA flow decreases significantly, changing to a continuous left-to-right flow at the third hour of life (top panel). These changes in DA flow cause the left ventricle to pump more blood than the right ventricle. As DA resistance increases over time (bottom panel), flow through the ventricles and lungs converge (top panel). Another consequence of changes in DA flow is the increasing difference between mean systemic and pulmonary arterial pressures, which can be observed between the second and 24th $\mathrm{h}$ after birth (middle panel).

\section{DISCUSSION}

We present a combination of a mathematical model and a time- and event-based script for educational simulation of fetal to early neonatal hemodynamic transitions. The pulsatile cardiovascular model presented by Beneken (1965, PhD thesis) was selected as a basis for this work because of its proven track record in simulating adult, infant, and neonatal cardiovascular physiology for educational simulation (1-4). Inclusion of the DA, FO, and placental flow was relatively straightforward. Other models of fetal cardiovascular physiology have been described in the past $(6,10)$, but because of their com-

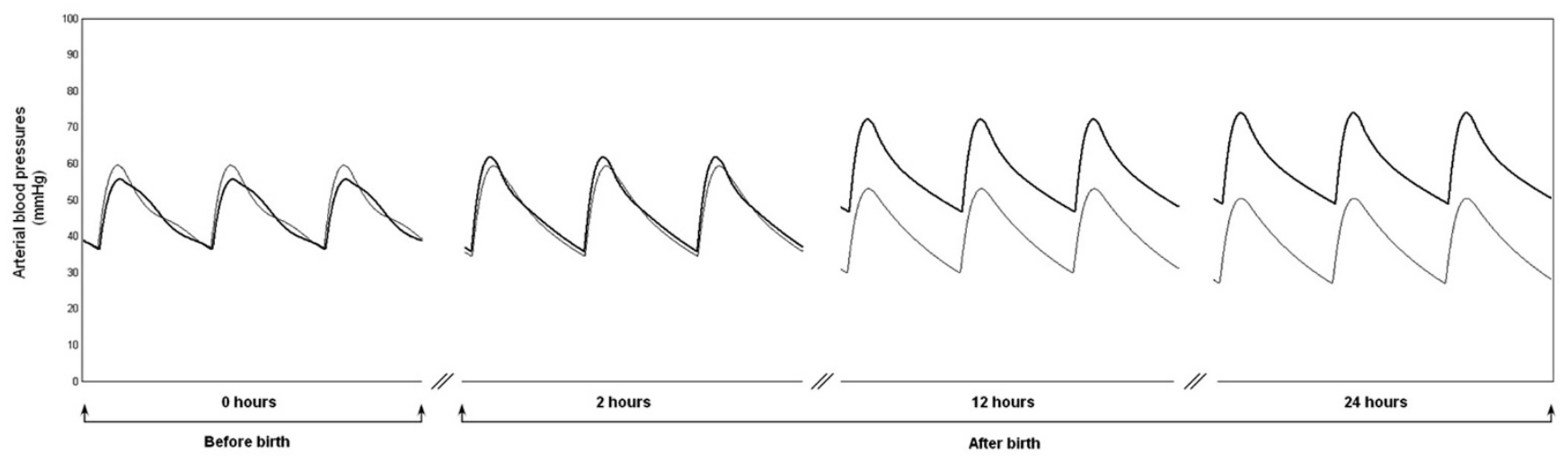

Figure 3. Simulated systemic (heavy line) and pulmonary (light line) arterial blood pressure before birth and at 2, 12 , and $24 \mathrm{~h}$ after birth. 


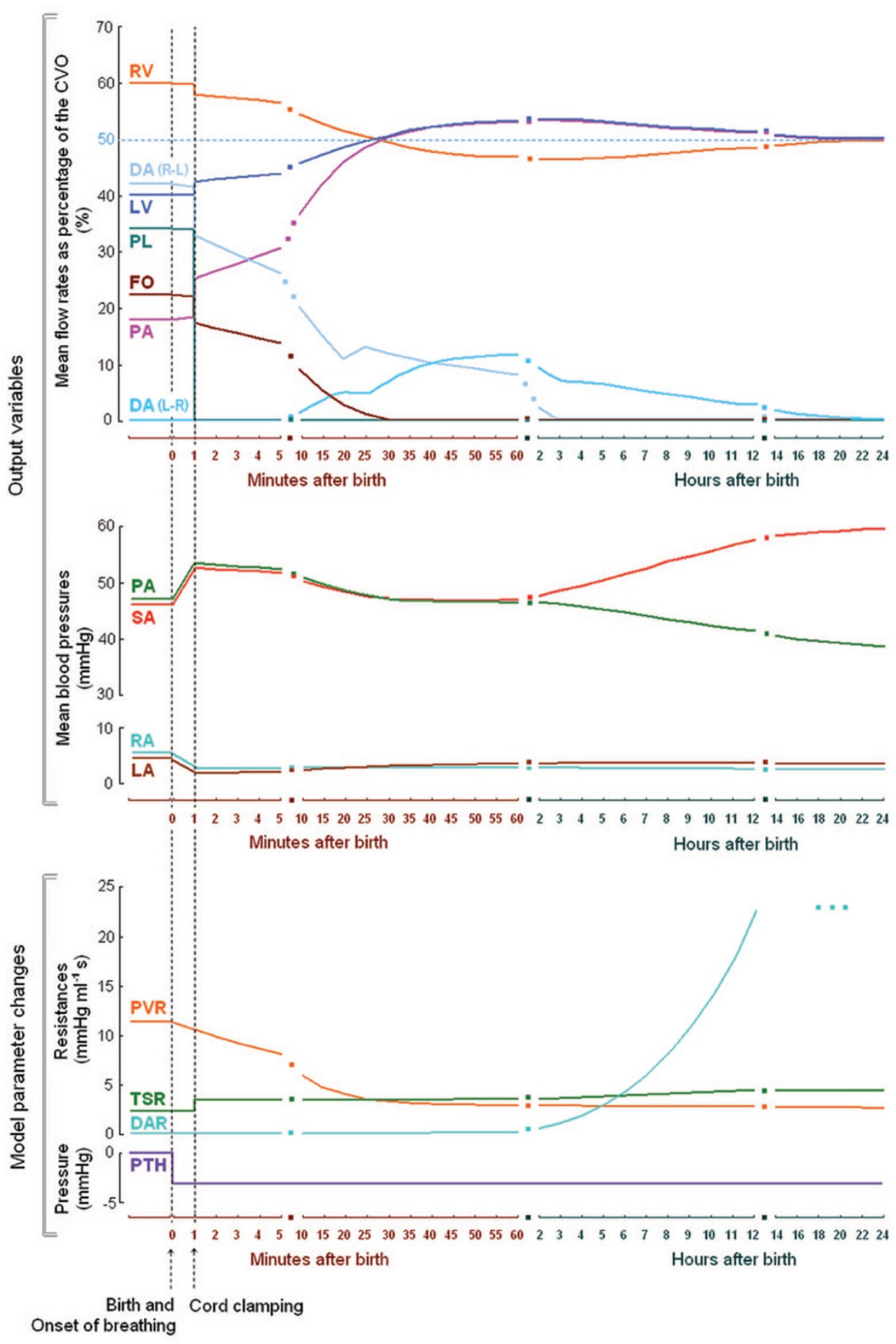

Figure 4. Simulated model parameter changes and output variables in the first $24 \mathrm{~h}$ after birth. $R V$, right ventricle; $D A$ (R-L), ductus arteriosus, right to left flow; $L V$, left ventricle; $P L$, placenta; $F O$, foramen ovale; $P A$, pulmonary arterial; $D A$ (L-R), ductus arteriosus, left to right flow; $S A$, systemic arterial; $R A$, right atrium; $L A$, left atrium; $P V R$, pulmonary vascular resistance; TSR, total systemic resistance; $D A R$, ductus arteriosus resistance; $P T H$, mean intrathoracic pressure. plexity and large parameter sets were judged to be difficult to apply in our envisioned educational application, which involves repeated parameter estimation and manipulation to represent different patients, pathologies, and critical situations. The relatively simple circulation model presented by Huikeshoven et al. (7) has a complex heart model. The structure of the presented model for a 24-h-old neonate is identical to that of a previously described 1-week-old neonate (2), but parameters differ considerably. This should in principle be exclu- sively because of the age difference, but an evaluation of the evolution from $24 \mathrm{~h}$ to 1 week is needed to confirm this statement.

Simulations results demonstrate that, in general, the model is capable of correctly representing fetal hemodynamics and its evolution during the first $24 \mathrm{~h}$ of life. The validation of events occurring shortly after birth (ventilation and cord clamping) is limited by the available experimental data, which do not completely represent normal physiologic conditions. 
Target data used for this purpose includes three sequential events: ventilation, oxygenation, and umbilical cord occlusion. Each event was continued for $15 \mathrm{~min}$, as described in the footnote of Table 3. To reproduce these conditions, a few adaptations in scripted parameters were needed: 1) matching to reported timeline; 2) representation of artificial ventilation with a positive average intrathoracic pressure of $+2 \mathrm{~mm} \mathrm{Hg}$ (instead of $-3 \mathrm{~mm} \mathrm{Hg}$ ). Intrathoracic pressure is positive throughout inspiration and remains slightly positive, whenever positive end-expiratory pressure is applied (15,37); and 3) delayed rise in DA resistance, corresponding to the initiation of ventilation with $100 \%$ oxygen. In these conditions, simulation results match the target data. The only exception is right-to-left DA flow during ventilation with cord clamping, which is higher than in target data. This may be explained by differences between species. Flow through the DA after birth may not be the same in the human neonate and in the newborn lamb. In the latter, the PVR apparently falls sharply within minutes after the onset of respiration, and the fetal direction of flow suddenly becomes reversed (38).

Figures 3 and 4 illustrate potential educational applications of the model and show its integrated response. Evolution of aortic and pulmonary artery pressures can be simulated in accelerated time, providing students with a unique experience of these important yet complex phenomena.

Potential limitations may result from the lack of sufficient experimental data and heterogeneity of available data to provide model parameters and compare simulation results with independent target data. However, despite different flow measurements techniques in animal and in human subjects, the simulation results provided fairly consistent values of the relative flow rates and pressures in the different parts of the circulation.

Manipulation of specific model parameters or inclusion of new input variables is straightforward and allows for simulation of relevant clinical acute scenarios. An increase in pulmonary peripheral resistance can be used to mimic persistent pulmonary hypertension and simulate a right-to-left ductal shunt. Conversely, combining a decrease of this parameter with a persistent DA leads to a significant left-to-right shunt with volume overload of the left heart and systemic hypotension as clinically relevant consequences. Another illustrative example is the use of the ventricular time-variant elastances to simulate myocardial depression. We refer to a previous article from our group, where several congenital heart defects are modeled using the same methodology (2).

Expansion of this model with transport of oxygen and carbon dioxide seems to be the most pressing future work, because it would allow for the simulation of other clinically relevant variables, such as oxygen saturations or blood $\mathrm{pH}$. As no baroreflex control mechanism has been incorporated yet, the current model precludes simulations of dynamic responses to blood loss or fluid expansion. Incorporation of natural control mechanisms (baroreflex and chemoreflex), congenital heart disease, or pathologies that may occur during the transitional period will further enhance its potential educational impact.
Envisioned educational applications for this model include interactive screen-based or full-body simulators. The specific interventions available in those simulators will be identified based on a more detailed training needs analysis and training program design. Such analyses are beyond the scope of this study. However, the selected model structure, variables, and parameters already anticipate a broad range of interventions. For instance, the inclusion of a mean intrathoracic pressure already anticipates the use of this model to train resuscitation procedures in a full-body simulator.

In conclusion, we present an original model for educational simulation of fetal to early neonatal hemodynamic transitions. Fetal and neonatal endpoints show realistic simulated hemodynamic variables. The transitions at birth and during the first $24 \mathrm{~h}$ of life are also represented realistically. This model constitutes an essential component of educational simulators for perinatal acute care. It can also be used to demonstrate the complex hemodynamic transitions at birth.

\section{REFERENCES}

1. Van Meurs WL, Good ML, Lampotang S 1997 Functional anatomy of full-scale patient simulators. J Clin Monit 13:317-324

2. Sá Couto CD, van Meurs WL, Goodwin JA, Andriessen P 2006 A model for educational simulation of neonatal cardiovascular pathophysiology. Simul Healthe $1: 4-9$

3. Zijlmans M, Sá-Couto CD, van Meurs WL, Goodwin JA, Andriessen P 2009 Corrected and improved model for educational simulation of neonatal cardiovascular pathophysiology. Simul Healthc 4:49-53

4. Goodwin JA, van Meurs WL, Sá Couto CD, Beneken JE, Graves SA 2004 A model for educational simulation of infant cardiovascular physiology. Anesth Analg 99:1655-1664

5. Ménigault E, Vieyres P, Lepoivre B, Durand A, Pourcelot L, Berson M 1997 Fetal heart modelling based on a pressure-volume relationship. Med Biol Eng Comput 35:715-721

6. Pennati G, Bellotti M, Fumero R 1997 Mathematical modeling of the human foetal cardiovascular system based on Doppler ultrasound data. Med Eng Phys 19:327-335

7. Huikeshoven F, Coleman TG, Jongsma HW 1980 Mathematical model of the fetal cardiovascular system: the uncontrolled case. Am J Physiol 239:R317-R325

8. Mielke G, Benda N 2001 Cardiac output and central distribution of blood flow in the human fetus. Circulation 103:1662-1668

9. Cunningham G, Leveno K, MacDonald P, Gilstrap L III, Gant N, Hankins G, Clark S 1996 The morphological and functional development of the fetus. In: Cunningham G, Leveno K, MacDonald P, Gilstrap III L, Gant N, Hankins G, Clark S (eds) Williams Obstetrics, 20th Ed. Appleton \& Lange, CT, pp 151-190

10. Huikeshoven FJ, Hope ID, Power GG, Gilbert RD, Longo LD 1985 Mathematical model of fetal circulation and oxygen delivery. Am J Physiol 249:R192-R202

11. Rasanen J, Wood DC, Weiner S, Ludomirski A, Huhta JC 1996 Role of the pulmonary circulation in the distribution of human fetal cardiac output during the second half of pregnancy. Circulation 94:1068-1073

12. Assali NS, Morris JA, Beck R 1965 Cardiovascular hemodynamics in the fetal lamb before and after lung expansion. Am J Physiol 208:122-129

13. Vilos GA, Liggins GC 1982 Intrathoracic pressures in fetal sheep. J Dev Physio 4:247-256

14. Hooper SB, Wallace MJ 2006 Role of the physicochemical environment in lung development. Clin Exp Pharmacol Physiol 33:273-279

15. Greenspan JS, Shaffer TH, Fox WW, Spitzer AR 1998 Assisted ventilation: physiologic implications and complications. In: Polin RA, Fox WW (eds) Fetal and Neonatal Physiology. Vol. 2. W.B. Saunders Company, Philadelphia, PA

16. Friedman AH, Fahey JT 1993 The transitions from fetal to neonatal circulation: normal responses and implications for infants with heart disease. Semin Perinatol 17:106-121

17. Ghanayem NS, Gordon JB 2001 Modulation of pulmonary vasomotor tone in the fetus and neonate. Respir Res 2:139-144

18. Dawes GS, Mott JC, Widdicombe JG, Wyatt DG 1953 Changes in the lungs of the new-born lamb. J Physiol 121:141-162

19. Brook MM, Heymann MA, Teitel DF 2001 The heart. In: Klaus MH, Fanaroff AA (eds) Care of the High-Risk. 5th ed. W.B. Saunders Company, Philadelphia, PA

20. Gutyon AC 1991 Fetal and neonatal physiology. In: Guyton AC (ed) Textbook of Medical Physiology. 8th ed. W.B. Saunders Company, Philadelphia, PA

21. Lagercrantz H, Bistoletti P 1977 Catecholamine release in the newborn infant at birth. Pediatr Res 11:889-893

22. Padbury JF, Diakomanolis ES, Hobel CJ, Perelman A, Fisher DA 1981 Neonatal adaptation: sympatho-adrenal response to umbilical cord cutting. Pediatr Res $15: 1483-1487$

23. Minoura S, Gilbert RD 1987 Postnatal change of cardiac function in lambs: effects of ganglionic block and afterload. J Dev Physiol 9:123-135 
24. Coskun S, Yüksel H, Bilgi Y, Lacin S, Tansug N, Onag A 2001 Non-invasive evaluation of the adaptations of cardiac function in the neonatal period: a comparison of healthy infants delivered by vaginal route and caesarean section. Acta Med Okayama 55:213-218

25. Kishkurno S, Takahashi Y, Harada K, Ishida A, Tamura M, Takada G 1997 Postnatal changes in left ventricular volume and contractility in healthy term infants. Pediatr Cardiol 18:91-95

26. Shiota T, Harada K, Takada G 2002 Left ventricular systolic and diastolic function during early neonatal period using transthoracic echocardiography. Tohoku J Exp Med 197:151-158

27. Walther FJ, Benders MJ, Leighton JO 1993 Early changes in the neonatal circulatory transition. J Pediatr 123:625-632

28. Hiraishi S, Misawa H, Oguchi K, Kadoi N, Saito K, Fujino N, Hojo M, Horiguchi Y, Yashiro K 1987 Two-dimensional Doppler echocardiographic assessment of closure of the ductus arteriosus in normal newborn infants. J Pediatr 111:755-760

29. Migliavacca F, Dubini G, Pennati G, Pietrabissa R, Fumero R, Hsia TY, de Leval MR 2000 Computational model of the fluid dynamics in systemic-to-pulmonary shunts. J Biomech 33:549-557

30. Teitel DF, Iwamoto HS, Rudolph AM 1987 Effects of birth-related events on central blood flow patterns. Pediatr Res 22:557-566
31. Anderson DF, Bissonnette JM, Faber JJ, Thornburg KL 1981 Central shunt flows and pressures in the mature fetal lamb. Am J Physiol 241:H60-H66

32. Agata Y, Hiraishi S, Oguchi K, Misawa H, Horiguchi Y, Fujino N, Yashiro K, Shimada N 1991 Changes in left ventricular output from fetal to early neonatal life. J Pediatr 119:441-445

33. Harada K, Shiota T, Takahashi Y, Tamura M, Takada G 1994 Changes in the volume and performance of the left ventricle in the early neonatal period. Early Hum Dev 39:201-209

34. Moss AJ, Emmanouilides GC, Adams FH, Chuang K 1964 Response of ductus arteriosus and pulmonary and systemic arterial pressure to changes in oxygen environment in newborn infants. Pediatrics 33:937-944

35. Emmanouilides GC, Moss AJ, Monset-Couchard M, Marcano BA, Rzeznic B 1970 Cardiac output in newborn infants. Biol Neonate 15:186-197

36. Emmanouilides GC, Moss AJ, Duffie ER Jr, Adams FH 1964 Pulmonary arterial pressure changes in human newborn infants from birth to 3 days of age. J Pediat 65:327-333

37. Soni N, Williams P 2008 Positive pressure ventilation: what is the real cost? Br J Anaesth 101:446-457

38. Moss AJ, Emmanouilides GC, Duffie ER Jr 1963 Closure of the ductus arteriosus in the newborn infant. Pediatrics 32:25-30 